\title{
EL OFICIO DE ESCRITOR
}

\author{
POR \\ RAUL PEREZ TORRES \\ Universidad Central del Ecuador, Quito
}

Si un hombre atravesara el paraíso en un sueño y se le diera una flor como prueba de que había estado allí, y si al despertar encontrara esa. flor... ¿Entonces qué? Esta frase, citada por Borges en boca de Coleridge, ¿no es quizá lo que más nos acerca a ese misterioso, tortuoso y desesperante oficio de escribir?

A mí al menos me sucede que muchos cuentos, muchos pasajes de novela han salido de mis manos justamente como en sueños, para encontrarme al otro día con esa flor (el texto), cuyos pétalos me impresionan por eso, porque era una flor percibida en sueños y que luego la encontraba tangible, viva, palpitante.

Particularmente nunca he podido organizar esquemas, teorías y todas esas cosas terriblemente serias y especializadas alrededor de la literatura; inclusive, la crítica estructuralista la he sentido en ciertos momentos como una autopsia sobre un muerto. El escritor, como todo ser humano, es una contradicción viva, permanente, y son quizá esas contradicciones las que me obligan a escribir, a dar paladas de ciego con las palabras, a buscarme y buscar mi conexión, mi comunicación con el mundo, que en la vida real se da cada vez más tenue y desorientada, tal vez por efectos de un sistema que nos alinea e individualiza hasta el punto de hacernos olvidar el ser social que llevamos dentro, aunque esta alineación también alimente de alguna manera, consciente o inconscientemente, el trabajo del escritor, más aún si sabemos que todo arte se desprende del contexto social e histórico en el que se desarrolla.

Creo que empecé a escribir por temor. Por el miedo que sentía al quedarme solo en mi dormitorio frente a una noche larga, eterna, poblada de fantasmas y de sombras. Allí comencé a planificar otros mundos, a leer 
e inmiscuirme en otras aventuras, a sentirme un gran titiritero que manejaba los hilos del mundo, de un mundo creado por mí y para mí, un mundo que quizá me alejaba dulcemente de lo prosaico, lo vulgar, lo agresivo, del mundo que encontraba al salir de mi cuarto, y que además me daba un pequeño poder, porque me permitía manejar la vida (la vida literaria) a mi antojo.

Más aún si se considera que había de por medio un carácter completamente introvertido, tímido, neurótico y hasta cobarde. Empecé a escribir entonces, a forjar historias en las cuales yo era siempre el héroe o el mártir, un juego que, a falta de amigos, me proporcionaba el placer de tenerlos y hacer de ellos lo que me viniera en gana. Luego, sin darme cuenta (como sucede con cualquier otro vicio), esa droga se fue metiendo en mí, de tal manera que ahora, cuando de alguna forma he derrotado al miedo y a la soledad rellenándola de jeroglíficos, cuando me he dado cuenta que la escritura es también un acto de solidaridad humana, un acto que nos lleva por laberintos oscuros al centro del hombre, que es un juego donde se potencializa la sensibilidad y el asombro, donde se reproduce como en un caleidoscopio el color de los pueblos y de los hombres, cuando he reflexionado sobre todo esto, digo, el miedo subsiste, pero es un miedo que se parece mucho al miedo que se siente cuando por primera vez vamos a hacer el amor. Miedo a que salga mal, a que no conectemos con el duende de la palabra, a que no seamos capaces en el terreno (es decir, en la hoja de papel, en el otro cuerpo) de demostrar y experimentar lo que tan claramente tenemos delineado en el cerebro y en el corazón. Porque la escritura, como cualquier manifestación de arte, es principalmente un acto de amor, y ese acto de amor se da en las transgresiones, ese terreno hermoso del erotismo, donde aparecen la muerte y la continuidad con una dialéctica obsesiva, donde se va sintiendo la voluptuosidad de la palabra, su poder de sugestión y de abrazo.

En este sentido, el acto de escribir es también un gesto de completa libertad, una libertad que como toda libertad tiene sus derechos y sus deberes, una libertad donde participa lo subjetivo y lo aparentemente extraño, pero todo dentro de una estructura que empieza siendo misteriosa (inclusive para el autor) y que luego se ensambla, se constituye, se resuelve, se revela bajo un código de sensaciones múltiples. Así, salgo de mi casa sin salir, convoco, construyo y afino personajes, que quizá no existen en la vida real, que apenas están construidos de ideas, pero que a la par han nacido de una experiencia real, que únicamente han sido restituidos a la realidad literaria (exagerada, enfermiza, qué sé yo) y que se van conformando como en un rompecabezas, tomando los ojos de Daniela, el gesto lúbrico de Marcela, la ternura de María, la combatividad de Quijano, la 
rebeldía del Fico o la desazón de Manuel; doy a esos personajes aliento, contradicción y zozobra, hasta que en un momento caminan por sí solos, me atrapan en su dialéctica tenaz y me siento uno más y todos, en el mismo juego de espejos que reproduce nuestra imagen con deformaciones distintas (Madame Bovary soy yo, decía Flaubert), y es posible que vaya encontrando incoherencias como las que se desprenden de los sueños, pero que quizá bien mirado no son incoherencias, sino la otra coherencia, la coherencia del texto literario que cada vez pide más sangre, más alimento para su cuerpo sofocado. Y lo mismo el personaje puede acostarse en una pensión de la Avenida 24 de Mayo en Quito y despertarse bajo el puente donde Horacio Oliveira bebía sidra junto a la Clochard, en París, que sentir auténticamente un dolor de muelas en el corazón, o hablar cara a cara con el espectro del padre de Hamlet, que reclama venganza. Esa es una de las cosas más bellas de la literatura, su ruptura lógica, su poder de ubicuidad, su visión totalizadora, su imagen de dios omnipotente. Por ello también, me parece que la literatura es una de las formas que tiene la historia para ensamblar la memoria, la memoria del hombre, la memoria de los pueblos. Ya lo decía alguien: cuando la realidad parece estar muriendo social e históricamente, es cuando surge esa necesidad de representaciones verbales de la realidad.

Uno escribe en la excitación, en el miedo que produce no solamente el ir en busca de la belleza, del amor o el desgarramiento, sino en el miedo que produce una soledad llena de multitudes, una soledad hecha de humo, de papeles blancos, donde los animalitos de las letras te pinchan y aprisionan con su inagotable impaciencia. Sí, uno escribe en la excitación, y esa excitación se parece mucho al amor de Dafnis y Cloe, quienes solamente conocieron la excitación, no el amor físico, no lo que lo provoca, y vivían en una constante excitación que hacía más eterna, más fosforescente, más dinámica, más obsesionante esa relación. $\mathrm{Y}$ es allí donde empieza el secreto de los cuentos de Borges y que él mismo se encargó de descifrar: en la literatura debe temblar la inminencia de una revelación que no se produce.

La naturaleza es un diccionario, corresponde al artista lo demás, decía Delacroix; nos corresponde desentrañarla, producir con la palabra una naturaleza humanizada, palabra como palabra y no como sustituto, palabra electrizada, en la cual la magia del verbo clave la idea, la afiance, la eternice, porque lo bello, ya se sabe, es la forma sensible de la idea.

Muchas veces me he sentido bloqueado frente a la máquina de escribir, con unas ganas locas de que suene el teléfono, de que mi mujer me busque, de que se incendie la casa, absorto frente a la máquina, en ese estado de estupor alcohólico donde la mente es más blanca que el papel 
y donde la única cosa que te acomete obsesiva es el pavor a la locura, al otro lado, a la «otredad»; pero con la ayuda del diablo, que vela por los escritores, he ido saliendo de la estupidez como se sale del agua, y una palabra me ha reconfortado, una línea me ha dado el preciso ritmo, una frase me ha sugerido el tono y el concepto, me ha revelado aquello de que yo estoy en el mundo para escribir, para testimoniar mi época, para incidir y buscar la identidad de lo que ocurre, para hacerme digno de la vida y su alborozo, y su tragedia. Entonces empiezan a hablar mis órganos, habla mi nariz y mi frente, mi vientre y mis manos, y me lleno de una literatura que obra en mí como el suero en el intoxicado, porque también esa literatura que se va formando se convierte en el sillón del psicoanalista, en el vaso del bebedor, en el bastón del ciego, y el texto va creciendo por sí mismo, adquiere sus alas propias, empieza a ser inteligible casi sin necesidad de reflexión, es decir, sin una reflexión fría o calculadora, y uno es el primer sorprendido de ver que la obra se ha desarrollado como una estructura autónoma y una economía interna que los críticos llaman nivel sincrónico.

Y pienso también que por este camino de la literatura me he librado de fantasmas, por ese camino me ha sido revelado el amor, por ese camino he descifrado la tarea de humanizar la vida, he buscado disolver mi individualidad y potenciarla en la multiplicidad, he descubierto mi rol social, que desde luego no acaba allí, sino que empieza.

Aunque escribir es también, a veces, asqueroso, te llenas de una asquerosa ternura, de un asqueroso pesimismo, de una asquerosa maldad, de una experiencia vergonzante de la que, sin embargo, casi siempre sales purificado, porque su alegoría te transforma. Y a mí me sucede una cosa que quizás sea melodramática y hasta cursi, pero que la digo porque está dentro de mi experiencia. Necesito sentirme bueno. Conmigo y con los demás. Todos los días que voy a escribir, empiezo por darme un paseo por los alrededores de mi casa, pienso en mi vida, me tomo cuentas, hago un balance, y en la desesperación frente a una maldad que siempre está en acecho, que siempre duerme a los pies del hombre, busco la cara de Dios, clamo por que la tierra me entregue su energía, por que el agua y el aire, el sol y la noche me transmitan su sencillez prodigiosa, y luego llego a mi escritorio, todavía nervioso, con un dolor punzante en el pecho, acomodo la máquina, afilo los lápices, dispongo las hojas, busco los cigarrillos, los fósforos, el café, cierro la puerta de mi escritorio, desconecto el teléfono, y, al revés de Bacon, ya inmiscuido en la soledad de la creación que he escogido para siempre, mi instinto se prende, y necesito escuchar a mi mujer en los otros cuartos canturreando su trabajo cotidiano, porque su actividad, su voz sencilla y desmixtificadora me serena, pone una ca- 
ricia sobre mi exaltación. Nos han contado que Ingres lloraba durante horas antes de empezar a pintar.

Alguna vez escribí figuradamente sobre las cosas que yo necesito para escribir, pero en realidad no se trataba de las cosas que allí enumeraba, se trataba únicamente de ejemplificar el miedo frente al oficio, el miedo y el embrujo, algo como el vértigo, como el crimen, como el salto en paracaídas. Un escritor joven me salió al paso luego de la lectura de ese texto y dijo que eso era una fantochada, que lo único que él necesitaba para escribir era papel y tinta. Tenía tanta razón (pero tan burda), que en homenaje a él, y con el riesgo de plagiarme, lo reproduzco aquí. Mi texto decía lo siguiente:

«... iMierda!, lo que yo necesito es una infraestructura para escribir. ¡Maldita sea, una infraestructura! Necesito un gran escritorio y una silla blanda, papel blanco que no tenga arrugas, que no tenga manchas, y muchos lápices de puntas afiladas, y necesito caminar sobre la lluvia sin mojarme, y encerrarme en el cuarto escuchando la música de Julio Jaramillo, lejana, vaga; necesito que mis pies estén calientes todo el tiempo y que la taza de café humee expresando su presencia. Necesito kilómetros de cigarrillos encendidos y que los fósforos al caer al cenicero no dejen su huella malévola, su cábala implacable; necesito que la máquina sea negra y que la letra $T$ quede justo a la altura del corazón, y también que al levantarme medio sonámbulo e idiota por la escritura secreta de la noche, asiente primero el pie izquierdo y no en aquella tabla diferente; necesito no mirarme al espejo sino después de la primera página para apreciar la huella que va dejando la grafía, no tocar el agua ni el fuego ni el aire ni la tierra. Necesito el silencio más absoluto (con la música de Julio como un recurso, como un pasado), paredes de corcho para que amortigüe las pisadas y las voces, necesito aire tibio que no permita filtraciones de ruido, necesito oler ajonjolí o amapola o por lo menos cartucho, y que sean tres, o cinco, o siete los besos que me has dado al dejarme; necesito no recordar tu perfil, Laura, ni tu voz, ni tu epidermis, necesito que mi mente esté en blanco, que no haya estrellas en el horizonte, ni luna, que no suene el teléfono ni la cadena del baño, necesito haber dormido (es un decir) toda la noche boca abajo y con las manos en el pecho; necesito recordar la última pesadilla, asegurarme que era literaria; necesito que ningún bicho me pique en la pierna ni en el brazo ni en la espalda, necesito ver los cuadros de la pieza bien dispuestos, más que todo el de Van Gogh, que siempre le da por amanecer chueco; que las cobijas, al dejarlas, no se asemejen a los mantos del Greco, es decir, que la realidad no copie del arte sus gestos solitarios; necesito recordar lo que pasará mañana, tres palabras necesito para empezar, o cinco, o siete, y también que 
me duela un poco la cabeza y el estómago; necesito fumar mucho, empezar a temblar, que el cerebro se me embote con el humo, que haya alguna planta cerca de mis ojos, pero que no se le ocurra retoñar en el momento en que la estoy mirando fijamente lelo; necesito plantas que no tengan hijos, que crezcan autónomas como las barbas de Quijano; necesito ponerme la camisa que en Cruz Loma le cayó un poco de jugo de mango, porque su olor permanece y me he escrito capítulos enteros con olor a mango, como aquel del conocimiento de Daniela; necesito un escritorio grande y una silla blanda, papel blanco que no tenga arrugas, que no tenga manchas; necesito tres palabras; necesito...»

Hasta aquí el artículo, que, mal interpretado y todo, incluí en uno de mis libros.

En cuanto a las formas, a los pequeños presagios, a las cábalas, tengo muchas y con ellas me bato desde que amanece. Prefiero escribir en las mañanas. La noche y el sueño obran como un filtro que cierne la imagen y la idea de una situación significante o que se vuelve significante por obra y gracia de la literatura. Y de igual manera siempre preferiría escribir en verano, aunque en el invierno hay algo que no se ha dicho nunca, como observa aquel poeta argentino enorme, casi desconocido en América, Mazzecchi.

En cuanto a los géneros, he incursionado en algunos de ellos, novela, teatro, poesía, a pesar de que piense que cada vez se van borrando más los límites impuestos por una preceptiva trasnochada y caduca, en todo caso quizás el género que nos escoge tenga mucho que ver con el carácter, con la idiosincrasia, con el temperamento. Siempre será ejemplificador lo que decía nuestro José de la Cuadra, uno de los mejores cuentistas de América; cuando le preguntaban por qué había escogido el cuento, él respondía: "Yo soy como los gallos, acabo pronto.» Sí, acabar pronto, decir las cosas como en un ataque, como en una convulsión, como en un abrazo, como en un espasmo. Es en el cuento donde mejor me siento, en el relato, en la historia corta. Allí mi espíritu se tensa como una cuerda de violín (a propósito, siempre recuerdo un símil del que nos hablaba un viejo profesor; él nos decía que la literatura es como un violín, las palabras son las cuerdas del violín, pero es una sola la caja de resonancia). El cuento es muchas cosas, pero ninguna de las que dice la teoría literaria; el cuento es una garrapata que nos camina en el corazón, en los intestinos, es la manera desdichada que tenemos de afianzar la melancolía de un instante. Contiene la duración de una lágrima, de un beso, de una bala. Es la mala pasada que nos hace la memoria, el hijo legítimo del recuerdo que ha dejado huella, es sacarse el escarabajo de la espalda, es como el bolsillo del payaso o el sombrero del mago, o la cartera de la mujer amada, donde 
siempre cabe algo que te sorprenderá. El cuento es un rayo, un deslumbramiento, una flecha encendida en la noche, una flecha que parte rauda hacia el corazón de la inteligencia. En el cuento pretendemos atrapar el espacio y el tiempo de un solo manotazo, en una cohesión donde cada palabra tiene el deber de ser inteligente, cada final una descarga eléctrica, buscando lo que buscaba Eliot, la plenitud de la fórmula verbal. Si la novela es extensa, el cuento es intenso. Quizá por ello amo también la poesía, por su breve estallido, por ese orden linguístico que define el misterio escondido en los hombres y las cosas, por su carácter subversivo, verídico, sin apariencia, porque rompe la paz interior, porque se escribe con todo el cuerpo, no a los lados ni al contorno, sino en profundidad; porque es el ejercicio de la excitación de la inteligencia, de la vigilia de la inteligencia, porque agudiza ( $\mathrm{y}$ a veces quiebra) todos los sentidos. Porque uno siente la muerte y la vida como en la culminación del coito, de su deslumbramiento.

Y luego el trabajo artesanal, el trabajo de orfebre, la necesidad de pulir y repulir la palabra no sólo con insistencia, sino con humildad, con la sencillez que practica el carpintero para hacer una silla, tratando de buscar la entonación precisa, el ritmo adecuado, la respiración del texto, a fin de que llegue al lector, ese monstruo de mil ojos, de la manera más directa, más sugestiva. Porque un libro empieza su circulación vital solamente cuando alguien lo lee.

Desde luego, el escritor es un insatisfecho, un contestatario, un vampiro nocturno que muchas veces se alimenta de su propia sangre. Su deseo no se colma, su obsesión no se serena, su desgarramiento no se precisa. A menudo lleva la culpa del mundo sobre sus hombros, y también la esperanza, esa forma que tiene el hombre de aligerar la condena. 
